RICYDE. Revista Internacional de Ciencias del Deporte doi: $10.5232 /$ ricyde

Rev. int. cienc. deporte

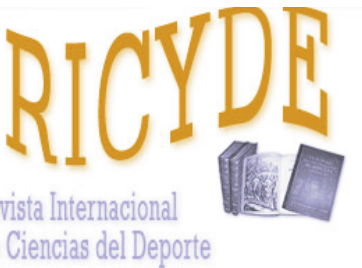

RICYDE. Revista Internacional de Ciencias del Deporte VOLUME XIII - YEAR XIII

Pages:397-408 ISSN:1885-3137

Issue 50 - October - 2017

\title{
Power-Load Curves in an Elite Weightlifter. A Case Study Curvas de carga-potencia en un halterófilo de élite. Estudio de caso
}

\author{
Francisco Javier Flores de Frutos ${ }^{1}$, Silvia Sedano-Campos ${ }^{2}$, Juan Carlos Redondo-Castán ${ }^{3}$
}

1.Servicio de Educación Física y Deportes. Universidad de Salamanca. España

2.Laboratorio de Fisiología. Universidad Europea Miguel de Cervantes. España

3. Facultad de Ciencias del Deporte. Universidad de León. España

\begin{abstract}
Findings from mechanical power data can make a significant difference in the performance of athletes in weightlifting if it is properly understood by coaches. The purpose of this study was to examine the powerload (P-L) curve in the snatch, clean, back jerk and jerk of an international-level Spanish weightlifter. Four testing sessions were conducted in the present work. Session 1: estimating snatch and clean 1RM (1 repetition maximum); Session 2: power assessment of the snatch and clean across a spectrum of loads (30\% to $100 \%$ ) of the predetermined 1RM; Session 3: estimating back jerk and jerk 1RM; Session 4: power assessment of the back jerk and jerk across a spectrum of loads ( $30 \%$ to $100 \%$ ) of the predetermined 1RM. The highest peak power output (Pmax) was reached with loads of $90 \%$ of 1 RM in each exercise tested, which demonstrated this percentage to be the optimal load (Pmax load) to train power development during weightlifting exercises.
\end{abstract}

Key words: snatch; clean; back jerk; jerk power; optimal load.

\section{Resumen}

El entendimiento por parte de los entrenadores de los datos de potencia mecánica obtenidos en la halterofilia puede marcar notables diferencias en el rendimiento de los atletas. El propósito de este estudio fue examinar la curva de carga-potencia en los ejercicios de arrancada, cargada, envión por detrás y envión en un halterófilo español de nivel internacional. Cuatro sesiones de evaluación fueron llevadas a cabo en este estudio. En la sesión 1 se estimó el 1RM (1 repetición máxima) en la arrancada y la cargada. En la sesión 2 se realizó una evaluación de la potencia alcanzada en la arrancada y la cargada en un espectro de cargas desde el $30 \%$ al $100 \%$ del 1RM predeterminado anteriormente. En la sesión 3 se estimó el $1 R M$ en el envión por detrás y el envión. En la sesión 4 se realizó una evaluación de la potencia alcanzada en el envión por detrás y el envión en un espectro de cargas desde el $30 \%$ al $100 \%$ del 1 RM predeterminado anteriormente. El pico de potencia mecánica fue alcanzado con el $90 \%$ del 1 RM en cada uno de los ejercicios, mostrando dicho porcentaje como la carga óptima para el desarrollo de la potencia en ejercicios de halterofilia.

Palabras clave: arrancada; cargada, envión; envión por detrás; potencia; carga óptima. 
Flores de Frutos, F. J.; Sedano-Campos, S., y Redondo-Castán, J. C. (2017). Power-Load Curves in an Elite Weightlifter. A Case Study. RICYDE. Revista internacional de ciencias del deporte, 50(13), 397-408. https://doi.org/10.5232/ricyde2017.05006

\section{Introduction}

$\mathrm{T}$ he ability to develop high levels of muscular power is considered one of the main determinants of athletic performance, especially in sports that include throwing, jumping and sprinting actions, which require high force generation in a short period of time. (Castillo, Valverde, Morales, Pérez-Guerra, De León, and García-Manso, 2012; Comfort, Fletcher and McMahon, 2012a; Cormie, McGuigan and Newton, 2011; Kawamori and Haff, 2004; Suchomel, Comfort and Stone, 2015; Suchomel, Wright, Kernozek and Kline, 2014). To maximize the power output during any exercise there must be an optimum relationship between force and velocity. Consequently, the optimal load to achieve maximum peak power output, is the load that elicits maximum power production in a given movement (Cormie et al., 2011). From a practical point of view, the Pmax load and similar loads with no significant differences between them, the optimum power spectrum (Castillo et al., 2012), are considered the most appropriate stimuli to improve the power developed in a specific technical action (Soriano, JiménezReyes, Rhea and Marín, 2015; Suchomel et al., 2015). Thus, to improve power production it is appropriate to use the Pmax load and similar loads achieved through multi-joint exercises, such as weightlifting exercises and their variations. According to this, searching for the Pmax load has a particular interest for strength and conditioning coaches.

Weightlifting exercises are one of the most effective ways to develop power output (Lake, Mundy and Comfort, 2014). In this sense, weightlifting exercises (snatch, clean $\&$ jerk) and their variants have proved to produce some of the highest average human power outputs among all resistance-training exercises (Garhammer, 1993; Hori, Newton, Nosaka and McGuigan, 2006; Kawamori and Haff, 2004; Kilduff, Bevan, Owen, Kingsley, Bunce, Bennett, and Cunningham, 2007; Stone, 1993). Therefore, in order to achieve a high level of performance, weightlifting exercises and their derivatives are generally used as training exercises in many sports (Hori, Newton, Nosaka and Stone, 2005; Janz and Malone, 2008) and in conditioning programmes (Comfort, Allen and Graham-Smith, 2011; Comfort, McMahon and Fletcher, 2013).

Weightlifting performance depends on how much weight the athlete can lift (one repetition maximum or $1 \mathrm{RM}$ ), not how much power the athlete can produce. However, the importance of power production has been reported to be a key factor in this sport. On these lines, Stone, Pierce, Sands and Stone (2006), stated that power production is the most significant factor in determining success in weightlifting. Likewise, Hori et al. (2005) indicated that success in weightlifting depends on the power applied to the barbell against high loads (high-load speed strength). According to previous studies (Garhammer, 1993; Stone et al., 2006), during weightlifting the Pmax load is achieved with high loads: thus, the Pmax load is a key factor in achieving success during these types of exercise.

Although for many years researchers and coaches have been trying to gain knowledge about power production and Pmax loads in resistance exercises, the results have been inconclusive and the controversy still continues. Hence, the literature reports a wide range of Pmax loads (expressed as a percentage of 1RM) during weightlifting exercises and variants of these, ranging from $30 \%$ to $90 \%$ of 1RM (Comfort et al., 2012a; Flores et al., 2017; Garhammer, 1993; Haines, McBride, Skinner, Woodall, Larkin, Kirby and Dayne, 2010; Kilduff et al., 2007; Naclerio, 2006; Pennington, Laubach De Marco and Linderman, 2010; Suchomel et al., 2014; Thomas, Kraemer, Spiering, Volek, Anderson 
Flores de Frutos, F. J.; Sedano-Campos, S., y Redondo-Castán, J. C. (2017). Power-Load Curves in an Elite Weightlifter. A Case Study. RICYDE. Revista internacional de ciencias del deporte, 50(13), 397-408. https://doi.org/10.5232/ricyde2017.05006

and Maresh, 2007). This controversy in the literature may in part be explained by numerous methodological differences affecting the studies, the equipment used, and the inclusion of only the barbell or of the entire system mass in calculations (Cormie, McBride and McCaulley, 2007), the varying strength levels of participants (Baker, 2001), the type of training and fibers composition (Izquierdo, Häkkinen, González Badillo, Ibáñez and Gorostiaga, 2002; Romero, Vila, Ferragut and Alcaraz, 2009), and technical proficiency (Naclerio, 2006). Furthermore, evidence-based knowledge of the use of weightlifting movements is limited in comparison with other studies where traditional resistance exercises like squats or bench presses have been evaluated. Thus, the search for Pmax loads during weightlifting exercises is of great interest for extending the knowledge of weightlifters, coaches and researchers, when designing training programmes that are more efficient and better adapted to the individual characteristics of the athlete.

One of the most widely used ways of discovering what improvements occur in power production is by means of strength-velocity $(\mathrm{S}-\mathrm{V})$, or power-load (P-L) curves, or both (Romero et al., 2009). However, there are no studies that show the exact load for achieving the Pmax load in weightlifting exercises, particularly with regard to elite level weightlifters. The present case offered an opportunity to examine a sports profile that is normally difficult for researchers to access (a senior Spanish record holder) in order to discover the type of loads on which the training of high performance weightlifters should focus. Therefore, the aim of the present study was to analyse and compare the PL curve in snatch, clean, back jerk and jerk, so as to determine the optimal load (Pmax load) needed to achieve maximum peak power output (Pmax) in an elite Spanish weightlifter. In line with previous research findings (Flores et al., 2017; Garhammer, 1993; Haines et al., 2010), it was hypothesized that the Pmax load would be achieved toward the heavier end of the P-L curve for the snatch, clean, back jerk and jerk, and that a strong relationship would exist between the power values and Pmax load for the clean movement and jerk movement.

\section{Methods}

\section{Participant}

The participant in the study was an elite weightlifter, currently the senior Spanish record holder in clean \& jerk (148 kg), and total $(265 \mathrm{~kg})$ as well as the former senior Spanish record in snatch $(121 \mathrm{~kg}$ ) in the $62 \mathrm{~kg}$ body weight category. According to his best weightlifting performance in competition his Sinclair coefficient was 387.76 (Sinclair, 1985). The descriptive characteristics of the participant and his best weightlifting performance are shown in Table 1. Prior to participating in the study, the athlete read and signed an informed consent protocol in accordance with guidelines set by the Human Subjects Review Committee at University of Salamanca. The study conformed to the principles of the World Medical Association's Declaration of Helsinki.

Table 1.- Descriptive data for the participant.

\begin{tabular}{lc}
\hline Age (years) & 34.3 \\
Height $(\mathrm{m})$ & 172.10 \\
Body mass during the tests $(\mathrm{kg})$ & 63.8 \\
Best snatch in competition $(\mathrm{kg})$ & 121 \\
Best clean \& jerk in competition $(\mathrm{kg})$ & 148 \\
Best Total Olympic in competition $(\mathrm{kg})$ & 265 \\
Best Sinclair coefficient in competition $(62 \mathrm{~kg}$ category) & 387.76 \\
Weightlifting experience (years) & 20.3
\end{tabular}


Flores de Frutos, F. J.; Sedano-Campos, S., y Redondo-Castán, J. C. (2017). Power-Load Curves in an Elite Weightlifter. A Case Study. RICYDE. Revista internacional de ciencias del deporte, 50(13), 397-408. https://doi.org/10.5232/ricyde2017.05006

\section{Procedures}

The study was conducted during the first part of the 2015 season, in the month of January. Four test sessions were carried out in the weightlifter's usual training environment to assess 1RM and P-L curves for the snatch, clean, back jerk and jerk. Before the start of each test session, the participant went through a standardized warmup composed of 5 minutes of light-intensity cycling followed by 5 minutes of series of dynamic stretches. After this general warm up, the participant engaged in 10 minutes of specific warm-up involving weightlifting movements with an unloaded barbell. In sessions one and two, the order of exercises assessed was first snatch, and second clean for both sessions. In sessions three and four the order of exercise assessed was first back jerk, and second jerk for both sessions. The selected order of the exercises was set taking into account the order used during competitions; first snatch, and second clean \& jerk. Thus, snatch movement was always performed first and clean, jerk, or both were performed in the second place. In each session 10 minutes of rest were allowed between exercises. This recovery period is similar to that applied in weightlifting competitions between the snatch, and the clean \& jerk movements. The study design is shown in Figure 1.

IRM testing (sessions one and three). The weightlifter's 1RM was obtained in accordance with the standardized protocol presented by Baechle and Earle (2008). The weightlifter had previously performed this test numerous times in conjunction with his normal training programme, for the purpose of monitoring strength development, and therefore he was fully familiar with the procedures of the test.

Power testing (sessions two and four). 2-4 days after his 1RM was established (the pause being intended to ensure an adequate recovery between sessions), a power test session was performed. After the warm-up exercise sets, the participant carried out a maximum effort repetition for each load, which was systematically increased through $30 \%, 40 \%, 50 \%, 60 \%, 70 \%, 80 \%, 90 \%$ and $100 \%$ of the participant's predetermined $1 \mathrm{RM}$. The recovery period between loads was determined by the lifter, but was in all cases between 3 and 5 minutes.

\begin{tabular}{|c|c|c|c|c|c|c|c|}
\hline Session & 1 & & 2 & & 3 & & 4 \\
\hline Objective & $1 \mathrm{RM}$ & (2) & Power Test & $\stackrel{0}{2}$ & 1RM & త్ర & Power Test \\
\hline $\begin{array}{l}\text { Outline } \\
\text { session }\end{array}$ & $\begin{array}{c}\text { Warm up } \\
\text { SNATCH } \\
\text { Rest (10 mins) } \\
\text { CLEAN }\end{array}$ & 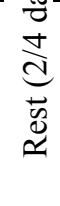 & $\begin{array}{c}\text { Warm up } \\
\text { SNATCH } \\
\text { Rest (10 mins) } \\
\text { CLEAN }\end{array}$ & 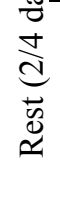 & $\begin{array}{c}\text { Warm up } \\
\text { JERK } \\
\text { Rest (10 mins) } \\
\text { BACK JERK }\end{array}$ & 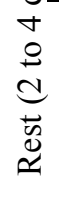 & $\begin{array}{c}\text { Warm up } \\
\text { JERK } \\
\text { Rest (10 mins) } \\
\text { BACK JERK }\end{array}$ \\
\hline
\end{tabular}

\section{Equipment}

Figure 1. Study Design.

A 3-axis accelerometer (PS-2136A, PASCO, Roseville, CA) operating at $100 \mathrm{~Hz}$ and a Bluetooth wireless device (Airlink 2 PS-2010, PASCO, Roseville, CA) were used in the power-testing sessions. The reliability of the results offered by these tests with the current measuring protocol has previously been validated (Flores, Sedano, de Benito and Redondo, 2016). This device was chosen for its easy portability in the weights room and minimum disturbance to the flow of the lifting sessions without compromising the weightlifter's technique in data collection (Sato, Smith and Sands, 2009). The accelerometer was placed with a foam unit underneath and in alignment with the long 
Flores de Frutos, F. J.; Sedano-Campos, S., y Redondo-Castán, J. C. (2017). Power-Load Curves in an Elite Weightlifter. A Case Study. RICYDE. Revista internacional de ciencias del deporte, 50(13), 397-408. https://doi.org/10.5232/ricyde2017.05006

axis of the barbell on the left edge of the bar in relation to the lifter's position (Figure 3). In that position, backward-and-forward, side-to-side, and up-and-down bar movements are equivalent to the $\mathrm{X}, \mathrm{Y}$ and $\mathrm{Z}$ axes respectively, in accordance with the factory configuration. Prior to each attempt, the position of the sensor unit was checked and, if necessary, restored to the configuration described above. The total mass of the measuring device plus the protective foam was $180 \mathrm{~g}$, which is equivalent to a metal barbell collar (Sato et al., 2009). This weight is not enough to induce asymmetric disturbances during a lift.

\section{Data Collection and Analysis}

The data were processed thereafter, using Pasco Capstone software (Version 1.1.5, Pasco Scientific PASCO, Roseville, CA) and barbell peak power outputs were calculated from acceleration in accordance with the methodology explained by Thompson and Bemben (1999). In accordance with Flores et al. (2016), data analysis included only the vertical acceleration attained by the barbell that was lifted, and only up to the finish of pull phase for snatch and clean, and up to the highest point of the bar's path before the catch position for back jerk and jerk. It should be noted that the lifter's body weight was not included in the calculations, so that the power calculations recorded the work done against the bar by the lifter. This exclusion of the body weight in the calculations gives more crucial information about weightlifting performance, because the success of weightlifting depends on the power applied to the barbell, which moves independently of the body, and on how high the lifter can pull the barbell (in the snatch and clean) or drive it (in the jerk), regardless of the lifter's body mass (Hori et al., 2006; Hori et al., 2007; Kawamori et al., 2005; McBride et al., 2011). In that sense, specific measurement of the power applied to the barbell may be the primary outcome measure when assessing weightlifting performance (Hori et al., 2006; Hori et al., 2007; Kawamori et al., 2005; McBride et al., 2011).

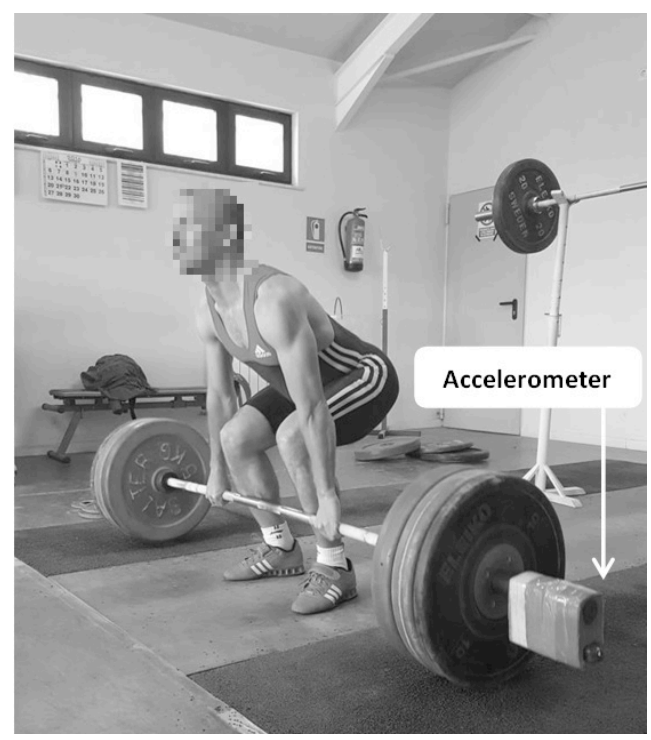

Figure 2. Weightlifter performing the lift with the accelerometer fixed to the bar as in Flores et al. (2016).

Hook grip, weightlifting belt, weightlifting shoes and chalk, were allowed for use by the participant, but weightlifting straps were not allowed. In both testing sessions, strong verbal encouragement was given to the participant to motivate him to perform each lift to the maximum and as powerfully as possible, so as to reach his top performance. 
Flores de Frutos, F. J.; Sedano-Campos, S., y Redondo-Castán, J. C. (2017). Power-Load Curves in an Elite Weightlifter. A Case Study. RICYDE. Revista internacional de ciencias del deporte, 50(13), 397-408. https://doi.org/10.5232/ricyde2017.05006

\section{Results}

Table 2 shows the data for each exercise during the power test session. Figure 2 presents the participant's P-L curve analysed in the snatch, clean, back jerk and jerk exercises. Peak power of the snatch, clean \& jerk increased progressively from $30 \%$ to $90 \%$ of $1 \mathrm{RM}$ and decreased strongly with the 1RM of the participant. The P-L curve of the back jerk showed two peaks, one with $60 \%$ and the other with $90 \%$ of 1 RM. During the four movements assessed, the lifter achieved the Pmax load with 90\% of $1 \mathrm{RM}$.

Table 2.- Descriptive data for power for snatch, clean, back jerk and jerk for each power test session.

\begin{tabular}{ccccc}
\hline & & \multicolumn{3}{c}{ Pmax (W) } \\
\hline $\begin{array}{c}\text { Load }(\% \\
1 \mathrm{RM})\end{array}$ & Snatch & Clean & Back Jerk & Jerk \\
\hline 30 & 1657.78 & 1129.89 & 1600.16 & 1137.71 \\
\hline 40 & 2016.63 & 2008.75 & 1817.56 & 1294.27 \\
\hline 50 & 2333.24 & 2182.10 & 2744.06 & 2031.18 \\
\hline 60 & 2670.43 & 2312.92 & 3075.14 & 2165.43 \\
\hline 70 & 2835.87 & 2490.06 & 2916.11 & 2367.70 \\
\hline 80 & 3072.66 & 2720.23 & 3101.71 & 2491.00 \\
\hline 90 & 3383.19 & 2945.90 & 3480.88 & 2963.82 \\
\hline 100 & 2716.78 & 2560.60 & 3077.05 & 2657.91 \\
\hline
\end{tabular}

* $\mathrm{RM}=$ repetition maximum

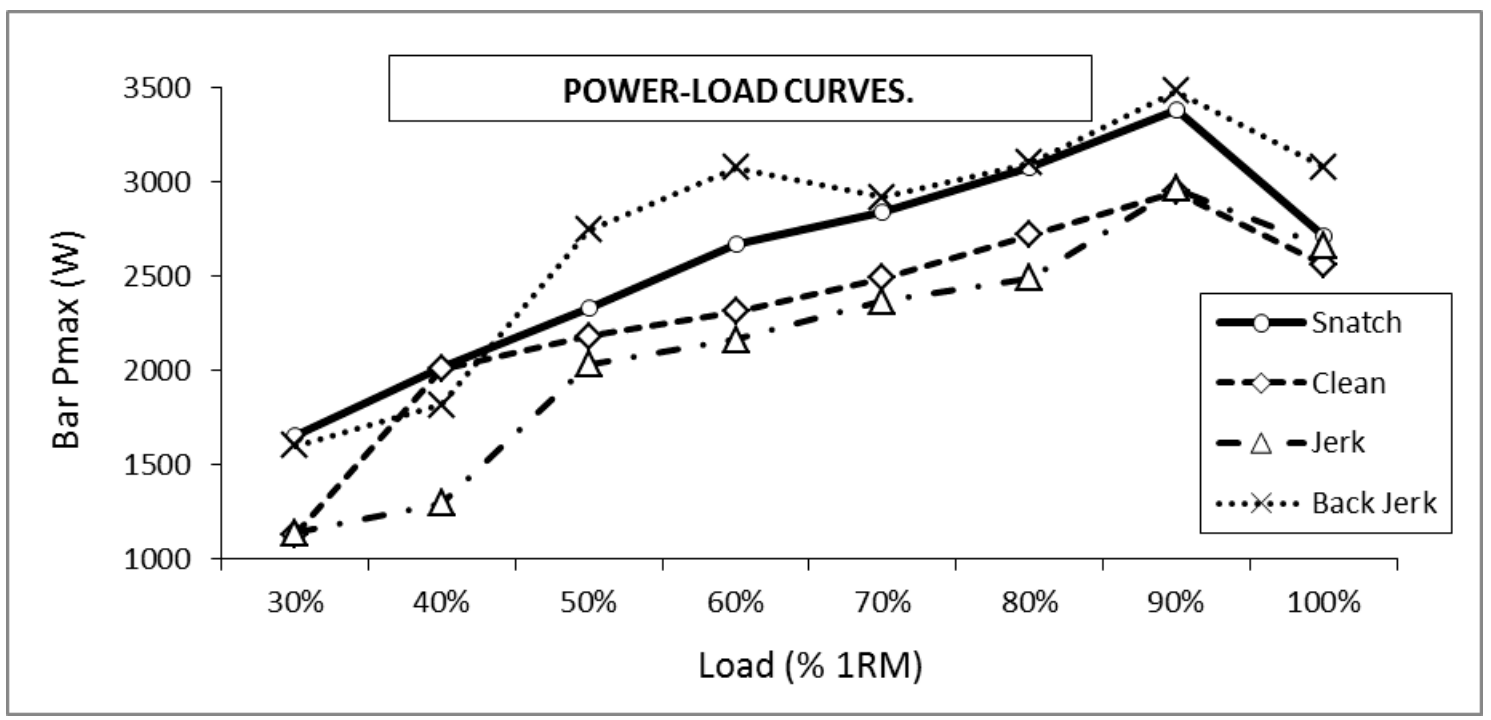

Figure 3.- P-L Curve of snatch, clean, back jerk and jerk. Pmax at loads of $30-100 \%$ of one repetition maximum (1RM).

The differences in bar velocity to achieve the Pmax load are shown in Figure 3, the snatch exercise being the movement where the bar velocity reached the highest value with $2.41 \mathrm{~m} / \mathrm{s}$. 
Flores de Frutos, F. J.; Sedano-Campos, S., y Redondo-Castán, J. C. (2017). Power-Load Curves in an Elite Weightlifter. A Case Study. RICYDE. Revista internacional de ciencias del deporte, 50(13), 397-408. https://doi.org/10.5232/ricyde2017.05006

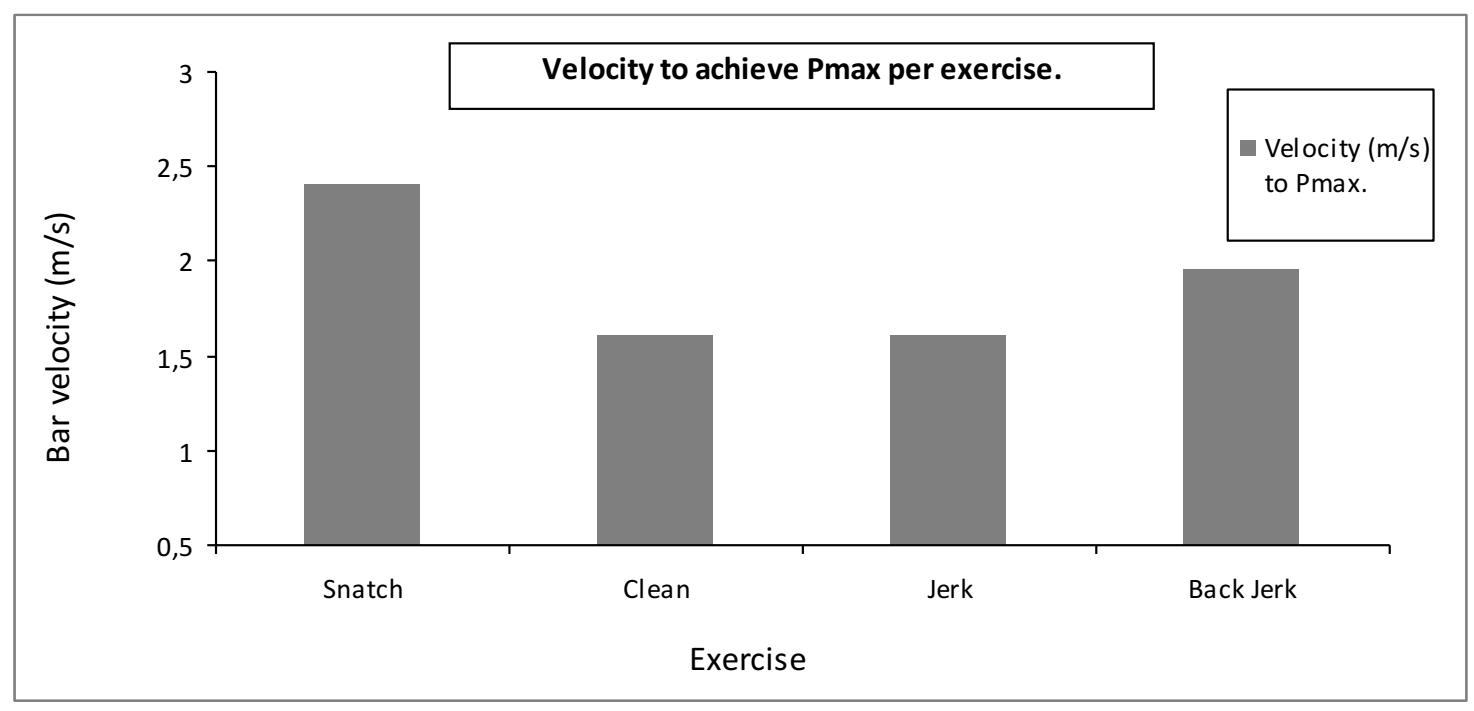

Figure 4.- Maximum bar velocity achieved per exercise tested.

\section{Discussion}

The purpose of this research was to describe and compare the P-L curve in snatch, clean, back jerk and jerk, so as to determine the optimal load (Pmax load) to achieve maximum peak power output (Pmax) in an elite Spanish weightlifter.

During weightlifting exercises, the centre of gravity of the barbell and the system (bar plus body mass) move independently of one another (Cormie et al., 2007; Hori et al., 2006; Hori et al., 2007; McBride et al., 2011). According to this, one of the weightlifter's interests is to move an external object, the bar plus weight, as fast as possible because success in weightlifting depends on the power applied to the barbell (Haines et al., 2010; Hori et al., 2006; McBride et al., 2011). Thus, only the power applied to the barbell was taken into account in the case under study. In this regard, taking into account only the power applied to the barbell, Pmax load during weightlifting exercises and their derivatives has been reported as ranging from $70 \%$ to 90\% of 1RM. (Flores et al., 2017; Haines et al., 2010; Hori et al., 2006; Naclerio, 2006). In the present study, the P-L curve showed Pmax loads with intensities of $90 \%$ of $1 \mathrm{RM}$ for all the exercises assessed. These results are consistent with the findings noted by McBride et al. (2011), who found 90\% of 1RM as the Pmax load with experienced strength athletes during power clean and by Flores et al. (2017), who also reported 90\% of 1RM as the Pmax load during the jerk and back jerk in a group of competitive weightlifters.

On the other hand, the findings of the current study are in contrast to some previous studies where the Pmax load during hang pulls and mid-thigh pulls was reported with significantly lower percentages of 1RM, ranging from 30\% to 60\% (Comfort et al., 2012b; Thomas et al., 2007). Although Olympics pulls are variants of weightlifting exercises, it is likely that the higher loads (90\% 1RM) identified in the current study to elicit Pmax during snatch, clean, back jerk and jerk are a result of the additional phases during the whole movement, permitting greater time and range of motion for accelerating the bar, technically unloading the bar because of its momentum (Comfort et al., 2012b). However, these differences should be interpreted with caution, because different systems for recording data and varying methodologies have been used for power calculations. 
Flores de Frutos, F. J.; Sedano-Campos, S., y Redondo-Castán, J. C. (2017). Power-Load Curves in an Elite Weightlifter. A Case Study. RICYDE. Revista internacional de ciencias del deporte, 50(13), 397-408. https://doi.org/10.5232/ricyde2017.05006

The lifter tested achieved the highest Pmax values during back jerk (3480.88 W) followed closely by the snatch $(3383.19 \mathrm{~W})$. It would appear that to date only one study (Flores et al., 2017) has studied Pmax values during back jerk. In that study, jerk and back jerk Pmax were compared, and the findings were in line with the current work, the highest Pmax being achieved during back jerk. The lowest Pmax was recorded for the clean $(2945.89 \mathrm{~W})$ and the jerk $(2963.82 \mathrm{~W})$, being almost equal for these two exercises. This finding is supported by previous research carried out by Garhammer (1993) and Suchomel et al. (2015), who reported that Pmax values during second pull of clean $\&$ jerk were very similar in magnitude for elite lifters in top physical condition. Although Pmax values were almost equal during snatch and back jerk (Figure 3), the bar velocity noted in achieving these Pmax values was clearly different, standing at 2.41 $\mathrm{m} / \mathrm{s}$ for the snatch and $1.96 \mathrm{~m} / \mathrm{s}$ for the back jerk (Figure 4). This important difference in bar velocities between the snatch and back jerk shows how in the first movement Pmax is reached with a greater bar velocity, while in the second it is the opposite, a slower strength-related movement.

During the current study, horizontal work was left out of consideration in all exercises assessed, account being taken only of the vertical component, in accordance with the methodology previously validated by Flores et al. (2016). According to Garhammer (1993), the horizontal work produced during the second pull in snatch and clean by a lifter of a light weight division, like the participant studied, represents a small component, less than $5 \%$, of the total work produced. On the other hand, during the jerk exercise, Garhammer (1993) claimed that the horizontal work can always be neglected for skilled lifters, as in the case of the athlete studied. This ruling out of the horizontal component of work during the current study should be kept in mind when comparing work in which both horizontal and vertical components were studied.

It is of interest to note that the percentages needed to elicit Pmax loads in the present work are likely to have been influenced by the profile of the participant studied (an elite Spanish weightlifter). The type of training and fibers composition, as well as the level of experience and proficiency of the participant, could shift the percentage of 1RM at which the highest power is produced either upwards or downwards (Izquierdo et al. 2002; Kawamori and Haff, 2004; Naclerio, 2006). In the present case, such factors include the probable predominance of fast twitch fibers, the background of the weightlifter studied in respect of technique, and the type of training usually undertaken in the sport of weightlifting, which focuses on applying high speed to the bar at high loads (Campos, Poletaev, Cuesta, Pablos, Carratala, 2006). These might contribute to a shift upwards in the percentage of 1RM needed to achieve Pmax (Naclerio, 2006).

The P-L curve for back jerk showed a different trend from the other three exercises assessed, with two different peaks on the curve, at 60\% and 90\% (Figure 3). Although no clear explanation can be given for the different trend shown during back jerk in comparison with the other three movements assessed, it may be hypothesized that this difference emerged from the varying background of technique in these several exercises. Thus, snatch, clean, and jerk are the competitive weightlifting movements which are in constant use by the participant tested, while back jerk is an auxiliary noncompetitive exercise which is used much less frequently (not more than once a week in the case of the weightlifter studied), which perhaps led to less technical consistency in this exercise. 
Flores de Frutos, F. J.; Sedano-Campos, S., y Redondo-Castán, J. C. (2017). Power-Load Curves in an Elite Weightlifter. A Case Study. RICYDE. Revista internacional de ciencias del deporte, 50(13), 397-408. https://doi.org/10.5232/ricyde2017.05006

In light of the results, the athlete studied should prioritize during his training work with loads close to $90 \%$ of the $1 \mathrm{RM}$ in the snatch, clean, back jerk and jerk exercises, because these percentages represent the Pmax load to achieve Pmax for the weightlifter studied. This percentage (90\%) represents a crucial part of the athlete's training, since the use of this intensity has been reported as a determining factor for success in weightlifting (González-Badillo, 1991). On the basis of the results obtained, the weightlifter studied should continue to focus on working with this range of percentages.

In order to detect possible variations in the results obtained, it would be of interest to periodize the evaluation of the athlete at least once a year. A greater frequency than this would not be necessary, since the tendency to modify the location of the Pmax load indicates that this variable needs longer periods of time (several years) to evince any major changes, although possibly these would occur more rapidly in less well trained subjects or those with lower levels of strength (Naclerio, 2006), this not being the case for the participant studied.

The findings of this study should be considered in light of two limitations. Firstly, the peak powers shown are referred only to the bar, although it is true that McBride et al. (2011) state that there is little difference between calculating the bar, the body or the system (lifter-plus-bar) power during weightlifting movements. Secondly, this investigation was limited to one case, an elite Spanish weightlifter. Thus, the findings of this study are applicable to the participant studied, but may not be valid for others.

\section{Conclusion}

It would appear that nobody has attempted to describe P-L curves including $100 \%$ of $1 \mathrm{RM}$ during snatch, clean, back jerk and jerk in an elite weightlifter. Likewise, there is a need for further studies describing what $\mathrm{P}-\mathrm{L}$ curves during weightlifting exercises should be like for different sports and levels where power training is a determinant factor, as is the case of weightlifting. On the basis of the outcomes of this investigation, and extrapolating only to the sample studied, it might be concluded that the weightlifter analysed in the snatch, clean, back jerk and jerk shows a P-L curve whose maximum peak power (Pmax) is reached with 90\% of 1RM for all exercises cited, identifying this percentage as the optimal load (Pmax load) for achieving maximum peak power output (Pmax), this percentage therefore being the best stimulus to develop and train power.

\section{References}

Baechle, T. R., \& Earle, R. W. (2008). Essentials of strength training and conditioning Human Kinetics.

Baker, D. (2001). A series of studies on the training of high-intensity muscle power in rugby league football players. Journal of Strength and Conditioning Research, 15(2), 198-209.

https://doi.org/10.1519/00124278-200105000-00008

Baker, D.; Nance, S., \& Moore, M. (2001a). The load that maximizes the average mechanical power output during explosive bench press throws in highly trained athletes. Journal of Strength and Conditioning Research, 15(1), 20-24. https://doi.org/10.1519/00124278-200102000-00004

Baker, D.; Nance, S., \& Moore, M. (2001b). The load that maximizes the average mechanical power output during jump squats in power-trained athletes. Journal of Strength and Conditioning Research, 15(1), 92-97. https://doi.org/10.1519/00124278-200102000-00016 
Flores de Frutos, F. J.; Sedano-Campos, S., y Redondo-Castán, J. C. (2017). Power-Load Curves in an Elite Weightlifter. A Case Study. RICYDE. Revista internacional de ciencias del deporte, 50(13), 397-408. https://doi.org/10.5232/ricyde2017.05006

Campos, J.; Poletaev, P.; Cuesta, A.; Pablos, C., \& Carratala, V. (2006). Kinematical analysis of the snatch in elite male junior weightlifters of different weight categories. Journal of Strength and Conditioning Research, 20(4), 843850.

Castillo, F.; Valverde, T.; Morales, A.; Pérez-Guerra, A.; De León, F., \& GarcíaManso, J. (2012). Maximum power, optimal load and optimal power spectrum for power training in upper-body (bench press): A review. Revista Andaluza de Medicina del Deporte, 5(1), 18-27.

https://doi.org/10.1016/S1888-7546(12)70005-9

Comfort, P.; Allen, M., \& Graham-Smith, P. (2011). Comparisons of peak ground reaction force and rate of force development during variations of the power clean. Journal of Strength and Conditioning Research, 25(5), 1235-1239. https://doi.org/10.1519/JSC.0b013e3181d6dc0d

Comfort, P.; Fletcher, C., \& McMahon, J. J. (2012a). Determination of optimal loading during the power clean, in collegiate athletes. Journal of Strength and Conditioning Research, 26(11), 2970-2974. https://doi.org/10.1519/JSC.0b013e318245bed4

Comfort, P.; McMahon, J. J., \& Fletcher, C. (2013). No kinetic differences during variations of the power clean in inexperienced female collegiate athletes. Journal of Strength and Conditioning Research, 27(2), 363-368. https://doi.org/10.1519/JSC.0b013e31825489c6

Comfort, P.; Udall, R., \& Jones, P. A. (2012b). The effect of loading on kinematic and kinetic variables during the midthigh clean pull. Journal of Strength and Conditioning Research, 26(5), 1208-1214. https://doi.org/10.1519/JSC.0b013e3182510827n

Cormie, P.; McGuigan, M. R., \& Newton, R. U. (2011). Developing maximal neuromuscular power. Sports Medicine, 41(1), 17-38. https://doi.org/10.2165/11537690-000000000-00000

Cormie, P.; McBride, J. M., \& McCaulley, G. O. (2007). The influence of body mass on calculation of power during lower-body resistance exercises. Journal of Strength and Conditioning Research, 21(4), 1042-1049. https://doi.org/10.1519/00124278-200711000-00011

Flores, F. J.; Sedano, S., \& Redondo, J. C. (2017). Optimal load and power spectrum during jerk and back jerk in competitive weightlifters. Journal of Strength and Conditioning Research, 31(3), 809-816. https://doi.org/10.1519/JSC.0000000000001544

Flores, F. J.; Sedano, S.; de Benito, A. M., \& Redondo, J. C. (2016). Validity and reliability of a 3-axis accelerometer for measuring weightlifting movements. International Journal of Sports Science and Coaching, 11(6), 872-879. https://doi.org/10.1177/1747954116676114

Garhammer, J. (1993). A review of power output studies of olympic and powerlifting: Methodology, performance prediction, and evaluation tests. Journal of Strength and Conditioning Research, 7(2), 76-89. https://doi.org/10.1519/00124278-199305000-00002

González-Badillo, J.J. (1991). Halterofilia. Comité Olímpico Español.

Haines, T.; McBride, J. M.; Skinner, J.; Woodall, M.; Larkin, T. R.; Kirby, T. J., \& Dayne, A. M. (2010). Effect of load on bar, body and system power output in the power clean. Journal of Strength and Conditioning Research, 24, 1. 
Flores de Frutos, F. J.; Sedano-Campos, S., y Redondo-Castán, J. C. (2017). Power-Load Curves in an Elite Weightlifter. A Case Study. RICYDE. Revista internacional de ciencias del deporte, 50(13), 397-408. https://doi.org/10.5232/ricyde2017.05006

Hori, N.; Newton, R. U.; Nosaka, K., \& McGuigan, M. R. (2006). Comparison of different methods of determining power output in weightlifting exercises. Strength and Conditioning Journal, 28(2), 34-40.

https://doi.org/10.1519/00126548-200604000-00006

Hori, N.; Newton, R. U.; Nosaka, K., \& Stone, M. H. (2005). Weightlifting exercises enhance athletic performance that requires high-load speed strength. Strength and Conditioning Journal, 27(4), 50-55.

https://doi.org/10.1519/00126548-200508000-00008

Hori, N.; Newton, R. U.; Andrews, W. A.; Kawamori, N.; McGuigan, M. R., \& Nosaka, K. (2007). Comparison of four different methods to measure power output during the hang power clean and the weighted jump squat. Journal of Strength and Conditioning Research, 21(2), 314-320. https://doi.org/10.1519/00124278-200705000-00005

Izquierdo, M.; Häkkinen, J.; González-Badillo, J. J.; Ibañez, J., \& Gorostiaga, E. M. (2002). Effects of long-term training specificity on maximal strength and power of the upper and lower extremities in athletes from different sports. European Journal of Applied Physiology, 87, 264-271. https://doi.org/10.1007/s00421-002-0628-y

Janz, J., \& Malone, M. (2008). Training explosiveness: Weightlifting and beyond. Strength and Conditioning Journal, 30(6), 14-22.

https://doi.org/10.1519/SSC.0b013e31818e2f13

Kawamori, N.; Crum, A. J.; Blumert, P. A.; Kulik, J. R.; Childers, J. T.; Wood, J. A., \& Haff, G. G. (2005). Influence of different relative intensities on power output during the hang power clean: Identification of the optimal load. Journal of Strength and Conditioning Research, 19(3), 698-708.

https://doi.org/10.1519/00124278-200508000-00035

Kawamori, N., \& Haff, G. G. (2004). The optimal training load for the development of muscular power. Journal of Strength and Conditioning Research, 18(3), 675684. https://doi.org/10.1519/00124278-200408000-00051

Kilduff, L. P.; Bevan, H.; Owen, N.; Kingsley, M. I.; Bunce, P.; Bennett, M., \& Cunningham, D. (2007). Optimal loading for peak power output during the hang power clean in professional rugby players. International Journal of Sports Physiology and Performance, 2(3), 260-269.

https://doi.org/10.1123/ijspp.2.3.260

Lake, J. P.; Mundy, P. D., \& Comfort, P. (2014). Power and impulse applied during push press exercise. Journal of Strength and Conditioning Research, 28(9), 2552-2559.

https://doi.org/10.1519/JSC.0000000000000438

McBride, J. M.; Haines, T. L., \& Kirby, T. J. (2011). Effect of loading on peak power of the bar, body, and system during power cleans, squats, and jump squats. Journal of Sports Sciences, 29(11), 1215-1221.

https://doi.org/10.1080/02640414.2011.587444

Naclerio, F. (2006). Análisis de la fuerza y la potencia mecánica producida en los ejercicios con resistencias en diferentes poblaciones de deportistas a lo largo de una temporada. (Doctoral dissertation).

Pennington, J.; Laubach, L.; De Marco, G., \& Linderman, J. (2010). Determining the optimal load for maximal power output for the power clean and snatch in collegiate male football players. Journal of Exercise Physiology, 13(2), 10-20.

Romero, S.; Vila, H.; Ferragut, C., \& Alcaraz, P. E. (2009). Power-strength curve in basketball players. Revista de Psicología del Deporte, 18(3), 425-428. 
Flores de Frutos, F. J.; Sedano-Campos, S., y Redondo-Castán, J. C. (2017). Power-Load Curves in an Elite Weightlifter. A Case Study. RICYDE. Revista internacional de ciencias del deporte, 50(13), 397-408. https://doi.org/10.5232/ricyde2017.05006

Sato, K.; Smith, S. L., \& Sands, W. A. (2009). Validation of an accelerometer for measuring sport performance. Journal of Strength and Conditioning Research, 23(1), 341-347. https://doi.org/10.1519/JSC.0b013e3181876a01

Sinclair, R. (1985). Normalizing the performance of athletes in Olympic weightlifting. Canadian Journal of Applied Sport Sciences, 10(2), 94-98.

Soriano, M. A.; Jiménez-Reyes, P.; Rhea, M. R., \& Marín, P. J. (2015). The optimal load for maximal power production during lower-body resistance exercises: A meta-analysis. Sports Medicine, 45(8), 1191-1205.

https://doi.org/10.1007/s40279-015-0341-8

Stone, M. H.; O’Bryant, H. S.; Mccoy, L.; Coglianese, R.; Lehmkuhl, M., \& Schilling, B. (2003). Power and maximum strength relationships during performance of dynamic and static weighted jumps. Journal of Strength and Conditioning Research, 17(1), 140-147.

https://doi.org/10.1519/00124278-200302000-00022

Stone, M. H. (1993). Position statement: Explosive exercise and training. Strength and Conditioning Journal, 15(3), 7-15. https://doi.org/10.1519/0744-0049(1993)015<0007:EEAT>2.3.CO;2

Stone, M. H.; Pierce, K. C.; Sands, W. A., \& Stone, M. E. (2006). Weightlifting: A brief overview. Strength and Conditioning Journal, 28(1), 50-66. https://doi.org/10.1519/00126548-200602000-00010

Suchomel, T. J.; Comfort, P., \& Stone, M. H. (2015). Weightlifting pulling derivatives: Rationale for implementation and application. Sports Medicine, 45(6), 823-839.

https://doi.org/10.1519/00126548-200602000-00010

Suchomel, T. J.; Wright, G. A.; Kernozek, T. W., \& Kline, D. E. (2014). Kinetic comparison of the power development between power clean variations. Journal of Strength and Conditioning Research, 28(2), 350-360.

https://doi.org/10.1519/JSC.0b013e31829a36a3

Thomas, G. A.; Kraemer, W. J.; Spiering, B. A.; Volek, J. S.; Anderson, J. M., \& Maresh, C. M. (2007). Maximal power at different percentages of one repetition maximum: Influence of resistance and gender. Journal of Strength and Conditioning Research, 21(2), 336-342.

https://doi.org/10.1519/00124278-200705000-00008

Thompson, C. J., \& Bemben, M. G. (1999). Reliability and comparability of the accelerometer as a measure of muscular power. Medicine and Science in Sports Exercise, 31(6), 897-902.

https://doi.org/10.1097/00005768-199906000-00020 